\title{
Elevated Parasympathetic Nerve Tone in Isoproterenol-Induced Neurally Mediated Syncope During Head-Up Tilt Testing
}

\author{
Asumi Takei, MD; Yoshio Ohnishi, MD; Mitsuhiro Yokoyama, MD
}

\begin{abstract}
To clarify the autonomic nerve mechanisms whereby isoproterenol induces vasovagal reaction, 32 patients with recurrent syncopal episodes of unknown origin underwent head-up tilt testing. Syncope was induced in 11 patients by a control tilt (control/+ group). The remaining 21 patients (control/- group) underwent the procedure during isoproterenol infusion. Syncope was induced in 13 (isoproterenol/+ group), but not in the remaining 8 patients (isoproterenol/- group). High-frequency component (HF) and low-frequency component (LF)/HF, which are indices of heart rate variability, were assessed for 2-min intervals at baseline (T1) during the initial phase (T2) and at the end (T3) of tilting in each test. The ratios of HF and LF/HF at T2/T1 and T3/T2 were calculated. The $\mathrm{HF}$ value at $\mathrm{T} 3$ in the control/+ group was greater than that in the control/- group $(1.47 \pm 0.91$ vs $0.75 \pm 0.34 ; \mathrm{p}<0.05)$. The HF value at T3 in the isoproterenol/+ group was significantly greater than those in the isoproterenol/- group $(1.19 \pm 1.04$ vs $0.43 \pm 0.23 ; \mathrm{p}<0.05)$. The $\mathrm{HF}$ value at $\mathrm{T} 2$ in the isoproterenol/ + tended to be greater than in the isoproterenol/- group $(1.30 \pm 0.85$ vs $0.66 \pm 0.53 ; \mathrm{p}=0.07)$. The ratio of $\mathrm{HF}$ for $\mathrm{T} 2 / \mathrm{T} 1$ in isoproterenol/+ was greater than in the other groups $(2.04 \pm 1.26$ in isoproterenol/+ vs $0.58 \pm 0.39$ in control/,$- 0.47 \pm 0.18$ in control/+ and $0.71 \pm 0.45$ in isoproterenol/ $-; \mathrm{p}=0.0001$ ), whereas that of $\mathrm{HF}$ for T3/T2 in the control/ + group was greater than in the other groups $(1.48 \pm 0.62 \mathrm{in}$ control/ + vs $0.97 \pm 0.33$ in control/-; $<<0.05,0.79 \pm 0.35$ in isoproterenol/- and $0.88 \pm 0.37$ in isoproterenol/ $+; \mathrm{p}<0.01$ ). No difference was observed in either $\mathrm{LF} / \mathrm{HF}$ or the ratio of $\mathrm{LF} / \mathrm{HF}$ among the groups. The early and persistent increase in parasympathetic nerve tone provoked by isoproterenol plays an important role in enhancing the vasovagal reaction during head-up tilt testing. (Jpn Circ J 2001; 65: 320-324)
\end{abstract}

Key Words: Autonomic tone; Heart rate variability; Neurally mediated syncope

$\mathbf{T}$ he cause of neurally mediated syncope, which is characterized by abrupt progressive hypotension and bradycardia, is unknown. Except during clinical episodes, patients with neurally mediated syncope usually have normal blood pressure control and normal neurohormonal findings associated with autonomic function! However, the autonomic mechanisms underlying the development of inappropriate cardioinhibitory and vasodepressor responses are not fully understood. Head-up tilt testing is a powerful tool with which to diagnose patients with unexplained syncope ${ }^{2}$ and, furthermore, an infusion of isoproterenol increases the sensitivity and shortens the duration of the test ${ }^{3-6}$ The activity of the autonomic nervous system during head-up tilt testing has recently been investigated. Heart rate variability (HRV) analysis has shown that syncopal patients have a distinctive autonomic response to the upright position,-15 but the autonomic response in HRV during isoproterenol infusion has not been studied in detail and remains unknown.

We examined the activities of the sympathetic and parasympathetic nervous systems during neurally mediated syncope induced using isoproterenol, then performed the head-up tilt test. We then examined the autonomic nervous activity preceding syncope using power spectral analysis of HRV.

(Received August 16, 2000; revised manuscript received December 13, 2000; accepted January 15, 2001)

First Department of Internal Medicine, Kobe University School of Medicine, Kobe, Japan

Mailing address: Yoshio Ohnishi, MD, 5-1, 7-chome, Kusunoki-chou, Chuo-ku, Kobe, Hyogo 650-0017, Japan. E-mail: ohnishi@med.kobeu.ac.jp

\section{Methods}

\section{Patients}

Thirty-two consecutive patients (male, $\mathrm{n}=14$; female, $\mathrm{n}=18$; mean age, 31 years) who underwent the head-up tilt test were referred to our laboratory for evaluation of recurrent episodes of syncopy of unknown origin. All patients underwent cardiovascular and neurological examinations including 12-lead electrocardiography, 24-h ambulatory monitoring and echocardiography. Electrophysiological studies were performed on 2 patients to rule out sick sinus syndrome and other brady- or tachy-arrhythmias.

We excluded patients with a clearly defined etiology for syncope, such as structural heart disease, metabolic disorders, diabetes mellitus, neuropathy and other conditions that may affect the autonomic nervous system. None of the patients were under medication.

\section{Head-Up Tilt Protocol}

Informed consent for head-up tilt testing was obtained from all participants. The patients did not consume food, caffeine or alcohol for at least $6 \mathrm{~h}$ before the test. Each patient was placed in the supine position and an intravenous catheter was inserted into the antecubital vein for isoproterenol infusion and, if necessary, for the administration of emergency medication. Standard electrocardiograms and noninvasive automated blood pressure values (JENTOW, Nippon Colin Corporation, Aichi, Japan) were automatically recorded for the entire duration of the study.

After resting in the supine position for $20 \mathrm{~min}$, the patient was tilted to an angle of 80 degrees (control tilt). If syncope was not induced within $15 \mathrm{~min}$, the patient was returned to 
Table 1 Patient Characteristics and Baseline Indices

\begin{tabular}{|c|c|c|c|c|}
\hline & \multirow{2}{*}{$\begin{array}{c}\text { Control/- } \\
(n=21)\end{array}$} & \multirow{2}{*}{$\begin{array}{c}\text { Control/+ } \\
(n=11)\end{array}$} & \multicolumn{2}{|c|}{ Control/- } \\
\hline & & & $\begin{array}{c}\text { Isoproterenol/- } \\
(n=8)\end{array}$ & $\begin{array}{c}\text { Isoproterenol/ }+ \\
(n=13)\end{array}$ \\
\hline Age (years) & $37 \pm 16$ & $29 \pm 15$ & $36 \pm 15$ & $38 \pm 15$ \\
\hline Gender $(M / F)$ & $10 / 11$ & $4 / 7$ & $3 / 5$ & $7 / 6$ \\
\hline Supine HR (beats/min) & $66 \pm 11$ & $63 \pm 6$ & $68 \pm 13$ & $65 \pm 10$ \\
\hline Supine $S B P(m m H g)$ & $118 \pm 15$ & $107 \pm 19$ & $110 \pm 15$ & $121 \pm 15$ \\
\hline Time to onset of syncope ( $\mathrm{min}$ ) & - & $9.6 \pm 4.3$ & - & $7.7 \pm 2.7$ \\
\hline Type of syncope (CI/MX/VD) & - & $4 / 6 / 1$ & - & $0 / 9 / 4$ \\
\hline
\end{tabular}

Data are mean values $\pm S D$ or number of patients. $H R$, heart rate; $S B P$, systolic blood pressure; $C I$, cardioinhibitory type; $M X$, mixed type; VD, vasodepressor type.

the supine position and an infusion of isoproterenol was started at a rate of $0.5 \mu \mathrm{g} / \mathrm{min}$ and gradually increased until a $25 \%$ increase in the baseline heart rate was achieved. After the heart rate had stabilized for $20 \mathrm{~min}$ in the supine position, the upright tilt was repeated (isoproterenol-tilt). The end-point of each tilt test was defined as the occurrence of syncope, secondary to hypotension or bradycardia, or the completion of $15 \mathrm{~min}$ of tilt. Patients also had to meet the following criteria during the test: sinus rhythm without sinoatrial or atrioventricular conduction disturbance and less than $1 \%$ extrasystoles.

\section{Grouping}

Based on the reaction to the control tilt, patients were divided into 2 groups; if syncope was induced, they were classified as control/t+, and if not, as control/-. Based upon the reaction to the isoproterenol-tilt, patients in the control/group were subdivided into isoproterenol/+ if syncope was induced, and if not, isoproterenol/-.

\section{HRV Analysis}

Three-lead electrocardiographic signals were continuously recorded on magnetic tape (TEAC, R-60, Tokyo, Japan) during the tilt tests and digitized at a sampling frequency of $1 \mathrm{kHz}$. The RR intervals were confirmed by visual inspection.

Power spectral densities (PSD) were estimated by fast Fourier transformation. At low frequency, power was integrated between 0.04 and $0.15 \mathrm{~Hz}$, and at high frequency, between 0.15 and $0.40 \mathrm{~Hz}$. We measured the areas of the low-frequency component (LF) and high-frequency component $(\mathrm{HF})$ as normalized PSD calculated by the following equation:

$$
\begin{aligned}
\text { normalized PSD } & =\operatorname{PSD}\left(\mathrm{ms}^{2}\right)^{1 / 2} \times 100 / \\
& \text { mean RR interval }(\mathrm{ms}) .
\end{aligned}
$$

We also calculated the $\mathrm{LF} / \mathrm{HF}$ ratio $(\mathrm{LF} / \mathrm{HF})$.

We analyzed these indices of HRV for each consecutive 2-min interval before and during tilting. Of these intervals, the following 3 time points were determined to evaluate alterations in autonomic tone: T1, just before tilting in the resting supine position; T2, the initial phase of tilting; and $\mathrm{T} 3$, just before syncope or the end of tilting. If the RR intervals immediately after tilting in T2 or signs of syncope in T3 were not steady enough for short-term analysis ${ }^{16}$ we shifted the 2-min interval forward for T2 analysis and backward for T3 analysis within a 15-s limit. Finally we assessed the ratio of $\mathrm{HF}$ and $\mathrm{LF} / \mathrm{HF}$, for T2/T1 (HF(T2/T1), LF/HF (T2/T1)) and for T3/T2 (HF(T3/T2), LF/HF(T3/T2)) using the following equation:
Control-tilt
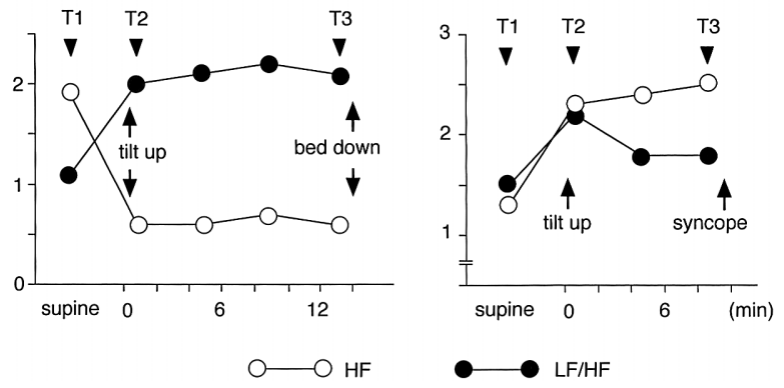

Fig 1. Time courses of HF and LF/HF in the control tilt and the isoproterenol-tilt of a 21-year-old male. Three time points were determined: T1, just before tilting in the resting supine position; T2, initial phase of tilting; and T3, just before syncope or at the end of tilting.

$$
\begin{aligned}
& \mathrm{HF}(\mathrm{Tn}+1 / \mathrm{Tn})=(\mathrm{HF} \text { in Tn+1)/(HF in Tn }) \\
& \mathrm{LF} / \mathrm{HF}(\mathrm{Tn}+1 / \mathrm{Tn})=(\mathrm{LF} / \mathrm{HF} \text { in } \mathrm{Tn}+1) /(\mathrm{LF} / \mathrm{HF} \text { in } \mathrm{Tn})
\end{aligned}
$$

where $n=1$ or 2 .

\section{Statistical Analysis}

Clinical characteristics and all HRV data are expressed as means $\pm \mathrm{SD}$. Multiple between-group comparisons of the mean values of the frequency domain parameters measured in each evaluation were performed using a one-way ANOVA test. Multiple comparisons were performed using the Fisher's protected LSD test when the F value was statistically significant by ANOVA. Comparisons within groups at each time point were tested by ANOVA. Comparisons were considered statistically significant when $\mathrm{p}<0.05$.

\section{Results}

In the control tilt, 11 patients (the control/+ group) developed neurally mediated syncope with characteristic symptoms of nausea, pallor, dizziness and a feeling of exhaustion followed by abrupt progressive bradycardia and hypotension. The remaining 21 patients (the control/group) underwent the isoproterenol-tilt and syncope was induced in 13 of these (the isoproterenol/+ group), but not in the remaining 8 (the isoproterenol/- group).

\section{Patient Characteristics and Baseline Indices}

Age, gender, baseline heart rate and systolic blood pressure did not significantly differ among the groups (Table 1). Mean time to the onset of syncope between the control/+ and isoproterenol/+ groups did not significantly differ. 


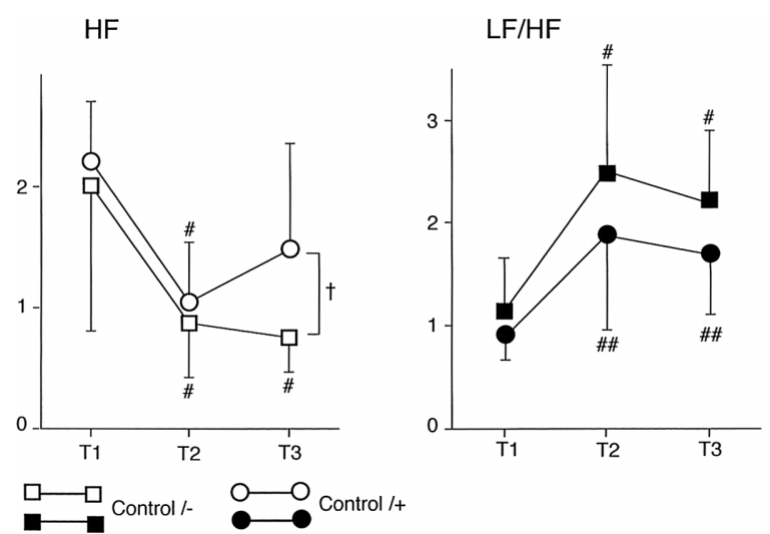

Fig 2. Changes of HF and LF/HF in the control/- and control/+ groups (mean $\pm \mathrm{SD})$. Significant within-group differences from T1 at $\mathrm{T} 2$ and $\mathrm{T} 3$ are indicated $\left({ }^{\#} \mathrm{p}<0.001,{ }^{\#} \mathrm{p}<0.05\right)$, as well as significant between-group differences at each time point $\left({ }^{\dagger} \mathrm{p}<0.05\right)$.

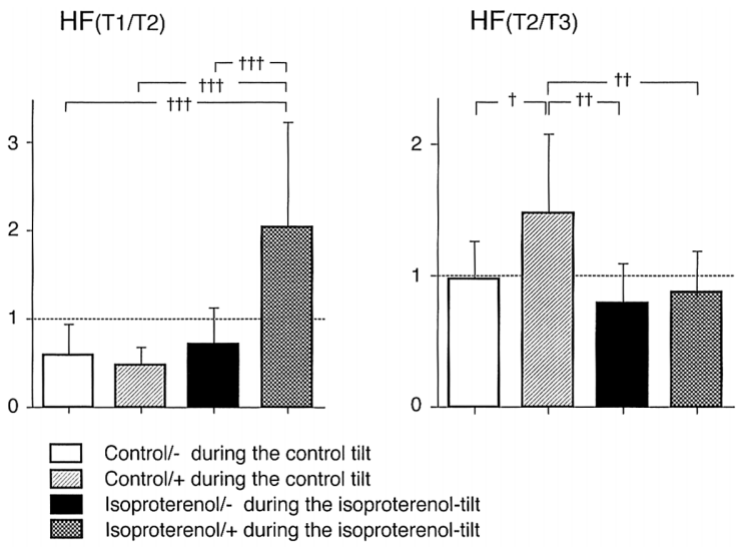

Fig 4. Ratios of HF for $\mathrm{T} 2 / \mathrm{T} 1$ and $\mathrm{T} 3 / \mathrm{T} 2$ in the 4 groups (mean $\pm \mathrm{SD}$ ). Significant between-group differences are shown $\left({ }^{\dagger} \mathrm{p}<0.05,{ }^{\dagger} \mathrm{p}<0.01\right.$, †े $=0.0001$ ).

Isoproterenol was used in 21 patients at doses ranging from 0.5 to $1.0 \mu \mathrm{g} / \mathrm{min}$.

A 21-year-old male is shown in Fig 1 as a representative case. Alterations in $\mathrm{HF}$ and $\mathrm{LF} / \mathrm{HF}$ are expressed as a series of 2-min intervals before and during tilting. This patient completed the control tilt without syncope, then developed syncope after $10 \mathrm{~min}$ of tilting with isoproterenol. In the control tilt, HF decreased and LF/HF increased immediately after tilting (T2). No remarkable change was observed in either $\mathrm{HF}$ or $\mathrm{LF} / \mathrm{HF}$ from $\mathrm{T} 2$ to $\mathrm{T} 3$. In the isoproterenol-tilt, HF increased from $\mathrm{T} 1$ to $\mathrm{T} 2$, then gradually increased until syncope occurred.

\section{HRV in Patients With and Without Syncope During the Control Tilt}

$\mathrm{HF}$ and $\mathrm{LF} / \mathrm{HF}$ were compared between the control/- and control/+ groups (Fig 2). The HF significantly decreased from $\mathrm{T} 1$ to $\mathrm{T} 2$ in both groups (from $2.01 \pm 1.27$ to $0.87 \pm 0.50$ in control/-, from $2.21 \pm 0.59$ to $1.05 \pm 0.55$ in control/4; $\mathrm{p}<0.001$, respectively). However, HF in the control/+ group increased from T2 to T3 (from $1.05 \pm 0.55$ to $1.47 \pm 0.91$; NS). Consequently, HF in T3 in the control/+ group was

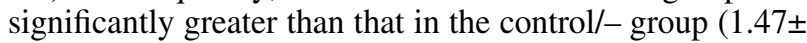
0.91 vs $0.75 \pm 0.34 ; \mathrm{p}<0.05)$. $\mathrm{LF} / \mathrm{HF}$ significantly increased

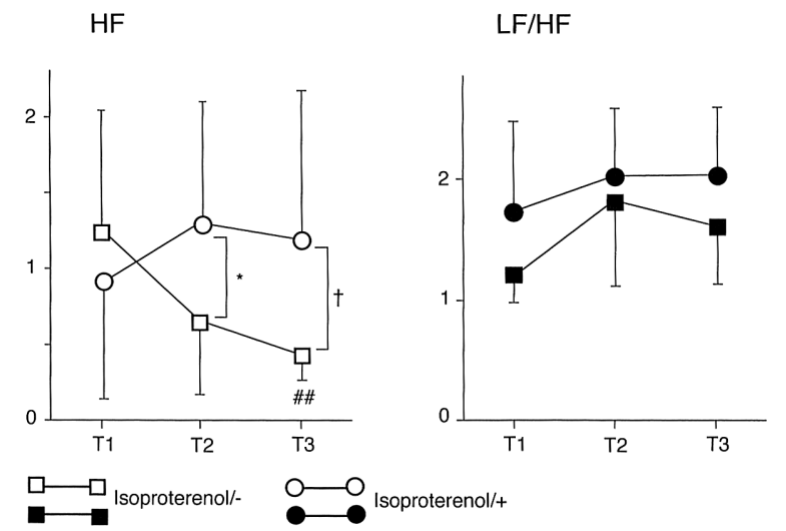

Fig 3. Changes of $\mathrm{HF}$ and LF/HF in the isoproterenol/- and isoproterenol/+ groups $($ mean $\pm \mathrm{SD})$. Significant within-group differences from $\mathrm{T} 1$ at $\mathrm{T} 2$ and $\mathrm{T} 3$ are indicated $(\# \mathrm{p}<0.05)$, as well as significant between-group differences at each time point $(\dagger \mathrm{p}<0.05)$. Difference between groups in $\mathrm{T} 2$ is denoted $(* \mathrm{p}=0.07)$.
$\mathrm{LF} / \mathrm{HF}(\mathrm{T} 1 / \mathrm{T} 2)$

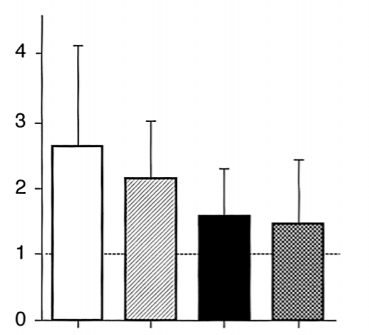

$\mathrm{LF} / \mathrm{HF}(\mathrm{T} 2 / \mathrm{T} 3)$

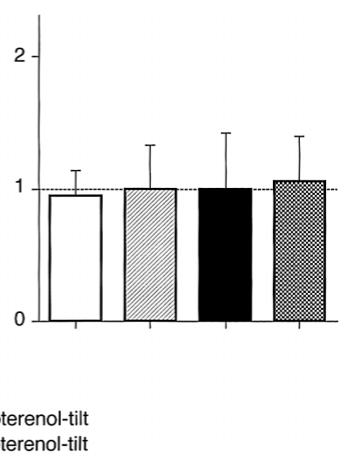

Fig 5. Ratios of LF/HF for $\mathrm{T} 2 / \mathrm{T} 1$ and $\mathrm{T} 3 / \mathrm{T} 2$ in the 4 groups (mean \pm $\mathrm{SD})$.

from T1 to T2 and T3 in both groups (from $1.13 \pm 0.57$ to $2.49 \pm 1.16$ and $2.19 \pm 0.76$ in control/,$- \mathrm{p}<0.001$; from $0.88 \pm$ 0.24 to $1.87 \pm 0.94$ and $1.69 \pm 0.65$ in control/ $+; \mathrm{p}<0.05)$. The $\mathrm{LF} / \mathrm{HF}$ ratio did not significantly differ between the groups $(1.13 \pm 0.57$ vs $0.88 \pm 0.24$ in $\mathrm{T} 1,2.49 \pm 1.16$ vs $1.87 \pm 0.94$ in T2, $2.19 \pm 0.76$ vs $1.69 \pm 0.65$ in T3; control/- vs control/+; NS, respectively).

\section{HRV in Patients With and Without Syncope \\ During the Isoproterenol-Tilt}

$\mathrm{HF}$ and $\mathrm{LF} / \mathrm{HF}$ were compared between the isoproterenol/- and isoproterenol/+ groups (Fig 3). The HF in the isoproterenol/- group decreased from T1 to T2 and T3, whereas in the isoproterenol/+ group it increased from $\mathrm{T} 1$ to $\mathrm{T} 2$ and remained at that level until syncope occurred in T3. As a result, the HF value at T3 in the isoproterenol/t+ group was significantly greater than in the isoproterenol/group $(1.19 \pm 1.04$ vs $0.43 \pm 0.23 ; \mathrm{p}<0.05)$. The HF value at $\mathrm{T} 2$ in the isoproterenol/+ group tended to be greater than in the isoproterenol/- group ( $1.30 \pm 0.85$ vs $0.66 \pm 0.53 ; \mathrm{p}=0.07)$. Twelve of the 13 patients $(92 \%)$ in the isoproterenol/t+ group showed marked a increase in $\mathrm{HF}$ at $\mathrm{T} 2$, whereas only 3 of the 8 patients $(38 \%)$ in the isoproterenol/- group did. The LF/HF ratio did not significantly differ between the groups $(1.19 \pm 0.26$ vs $1.72 \pm 0.76$ in $\mathrm{T} 1,1.82 \pm 0.75$ vs $2.02 \pm$ 
0.65 in $\mathrm{T} 2,1.61 \pm 0.51$ vs $2.03 \pm 0.69$ in $\mathrm{T} 3$; isoproterenol/vs isoproterenol/+; NS, respectively).

\section{Ratio of HF and LF/HF During the Control \\ Tilt and the Isoproterenol-Tilt}

Fig 4 and 5, respectively, show the ratio of $\mathrm{HF}$ and $\mathrm{LF} / \mathrm{HF}$ for the control/- and control/+ groups and for the isoproterenol/- and isoproterenol/+ groups. The ratio of HF for $\mathrm{T} 2 / \mathrm{T} 1$ (HF(T2/T1)) in the isoproterenol/+ group was significantly greater than in the other groups $(2.04 \pm 1.26$ in isoproterenol/+ vs $0.58 \pm 0.39$ in control/,$- 0.47 \pm 0.18$ in control/+ and $0.71 \pm 0.45$ in isoproterenol/-; $\mathrm{p}=0.0001$, respectively). The ratio of HF for T3/T2 (HF (T3/T2)) in the control/+ group was also significantly greater than in the other groups $(1.48 \pm 0.62$ in control/+ vs $0.97 \pm 0.33$ in control/-; $<<0.05,0.79 \pm 0.35$ in isoproterenol/- and $0.88 \pm$ 0.37 in isoproterenol/+; $p<0.01$, respectively; Fig 4). The ratio of LF/HF did not significantly differ either for T2/T1 (LF/HF (T2/T1); 2.64 \pm 1.58 in control/-, 2.16 \pm 0.96 in control/+, $1.58 \pm 0.77$ in isoproterenol/- and $1.47 \pm 1.02$ in isoproterenol/+), or for T3/T2 (LF/HF(T3/T2); 0.94 \pm 0.21 in control/-, $1.00 \pm 0.36$ in control/,$+ 1.00 \pm 0.44$ in isoproterenol/ - and $1.05 \pm 0.36$ in isoproterenol/ + ) among the 4 groups (Fig 5).

\section{Discussion}

This is the first study to demonstrate a distinctive HRV in the vasovagal reaction induced by a isoproterenol-tilt compared with that induced by a control tilt alone. In the control tilt, HF decreased from $\mathrm{T} 1$ to $\mathrm{T} 2$ irrespective of the results. However, HF in the control/+ group also increased from T2 to T3, but not in the control/- group. Even during isoproterenol infusion, $\mathrm{HF}$ decreased from $\mathrm{T} 1$ to $\mathrm{T} 2$ and $\mathrm{T} 3$ in patients without syncope, in the same manner as for the control tilt. On the other hand, HF in the isoproterenol/+ group demonstrated a remarkable increase in the early phase of tilting, and this level persisted until syncope occurred. These are the major findings in this study.

The autonomic nervous system plays an important role in the pathophysiology of neurally mediated syncope and several mechanisms have been proposed, ,8,17-22 Venous pooling while standing or tilting causes an excessive reduction in preload, which induces hypercontractility of the left ventricle and transient excessive stimulation of cardiopulmonary mechanoreceptors. Afferent signals in vagal C-fibers cause reflex reduction in sympathetic tone and increased vagal activity. Alternative non-cardiac triggers, including psychological factors, vasopressin release, carotid sinus baroreceptors, and pulmonary mechanoreceptors, have also been suggested?2

Normal individuals who do not develop tilt-induced syncope show withdrawal of parasympathetic tone in the HRV during the upright tilt test and LF/HF increases, whereas HF decreases, from the resting supine position to tilting!1,23-29 Our findings in the control/- and isoproterenol/groups were consistent with these published studies.

Some investigators have studied HRV during vasovagal reaction and found that parasympathetic tone, as assessed by time domain parameters or HF, is unlikely to decrease preceding syncope, while changes in sympathetic indices such as LF/HF have been conflicting?-15 In those studies however, most patients had an attack without isoproterenol infusion, and with regard to the alteration in parasympathetic tone during the control tilt alone, our findings are consistent with those previous results. Although isoproterenol is considered to elicit neurally mediated syncope during head-up tilt testing, no systematic report has described the changes in frequency domain in HRV compared with syncope induced by the control tilt alone. Lippman et al noted that failure of withdrawal in parasympathetic tone, as assessed by the root-mean-square of successive differences in the RR intervals (RMSSD) using time domain measurement of HRV, in response to upright tilt predicts a control-positive and isoproterenol-positive tilt response? They noted that the absence of a decrease in RMSSD in response to orthostatic stress had $100 \%$ specificity and $41 \%$ sensitivity for predicting a positive test result, but their study did not include data acquired during isoproterenol infusion. Boulos et al analyzed HRV in the frequency domain during the 256 beats preceding the onset of syncope with and without isoproterenol infusion 15 They noted a marked increase in the HF component prior to tilt-induced syncope, but could not distinguish patients with isoproterenol-induced vasovagal reactions from those who developed the reaction during the control tilt. The HRV analysis at $\mathrm{T} 2$ and $\mathrm{T} 3$ in the present study revealed that a persistently high level of HF during the upright position was related to the attack in patients with isoproterenol-induced vasovagal reaction. The remarkable increase of HF during the initial phase of tilting suggests that failure to withdraw parasympathetic tone appears at a very early phase in the isoproterenol-tilt and that analysis of HF during the initial tilt period could predict a positive response. There is an important difference between previous studies and the present study in the time period analyzed. Lippman et al analyzed the ECG at $5 \mathrm{~min}$ after tilting and Boulos et al did so just before syncope. In contrast, we analyzed the ECG at $2 \mathrm{~min}$ after tilting and we consider that the previous studies may have 'lost' the decrease in HF power observed during the early phase of tilting.

The combination of increased inotropic state caused by isoproterenol and reduced central volume by tilting accentuates the afferent activity of mechanoreceptors and the resulting reflex. Our results suggest that the early elevation and then persistent increase in HF induced by tilting under isoproterenol infusion easily reached the threshold of syncope. Further study of the role of the early elevation of $\mathrm{HF}$ power in isoproterenol-induced syncope is required.

The absolute powers in HF and LF may vary with the timing of the test, the patient's physical condition, psychological effects, etc. Furthermore, the baseline level of autonomic tone in the supine position cannot predict syncope induced after tilting. To compare the autonomic response in HRV during head-up tilt testing between patients under each variable condition, we defined the 'ratio' of HF and $\mathrm{LF} / \mathrm{HF}$ as universal indices in this study $($ Figs 4,5$)$ to enable a comparison of the response between syncopal patients with and without an isoproterenol infusion. The ratio of HRV generated data that more reliably clarified the mechanisms of autonomic nervous system activity.

From the viewpoint of $\mathrm{LF} / \mathrm{HF}$, neither the absolute values nor the ratios at each time point differed significantly between the groups in contrast to other restricted studies! $19,20,30$ Although increased sympathetic nervous activity with respect to catecholamine levels was followed by an abrupt withdrawal of muscle and neuronal sympathetic activity in patients with syncope, the change of HRV is controversial. Our study showed no difference in LF/HF among the 4 study groups. 
In conclusion, an early and persistent increase in parasympathetic nerve tone activated by isoproterenol plays an important role in enhancing the vasovagal reaction during head-up tilt testing.

\section{Study Limitations}

First, isoproterenol infusion is considered to decrease the specificity of head-up tilt testing. Natale et al reported that a positive response to head-up tilt testing during isoproterenol infusion at $5 \mu \mathrm{g} / \mathrm{min}$ was observed in $56 \%$ of subjects with no history of syncope, although the rate of positive response under low-dose isoproterenol was only $4 \%$. Therefore, we used a low-dose isoproterenol infusion to avoid false-positive responses. Second, it is known that LF/HF reflects the sympathetic nerve tone, which is affected by the parasympathetic nerve tone. Although $\mathrm{LF} / \mathrm{HF}$ is regarded as a marker of changes in sympatho-vagal balance, we use the LF/HF as an index of sympathetic nerve tone.

\section{References}

1. Jardine DL, Melton IC, Crozier IG, Bennett SI, Donald RA, Ikram $\mathrm{H}$ : Neurohormonal response to head-up tilt and its role in vasovagal syncope. Am J Cardiol 1997; 79: 1302-1306

2. Almoquist A, Goldenberg IF, Milstein S, Chen MY, Chen X, Hansen $\mathrm{R}$, et al: Provocation of bradycardia and hypotension by isoproterenol and upright posture in patients with unexplained syncope. $N$ Engl J Med 1989; 320: 346-351

3. Grubb BP, Kosinski D, Temesy-armos P, Brewster P: Responses of normal subjects during 80 degree head upright tilt table testing with and without low dose isoproterenol infusion. Pacing Clin Electrophysiol 1997; 20: 2019-2023

4. Morillo CA, Klein GJ, Zandri S, Yee R: Diagnostic accuracy of a low dose isoproterenol protocol. Am Heart J 1995; 129: 901-906

5. Natale A, Akhtar M, Jazayeri M, Dhala A, Blanck Z, Deshpande S, et al: Provocation of hypotension during head up tilt testing in subjects with no history of syncope or presyncope. Circulation 1995; 92: $54-58$

6. Sheldon R, FRCP (C), Killam S: Methodology of isoproterenol tilt table testing in patients with syncope. J Am Coll Cardiol 1992; 19: $773-779$

7. Lippman N, Stein KM, Lerman BB: Failure to decrease parasympathetic tone during upright tilt predicts a positive tilt-table test. Am J Cardiol 1995; 75: 591-595

8. Lipsitz LA, Mietus J, Moody GB, Goldberger AL: Spectral characteristics of heart rate variability before and during postural tilt: Relations to aging and risk of syncope. Circulation 1990; 81: 1803-1810

9. Nelson SD, Stanley M, Love CJ, Coyne KS, Schaal SF: The autonomic and hemodynamic effects of oral theophylline in patients with vasodepressor syncope. Arch Intern Med 1991; 151: 2425-2429

10. Theodorakis GN, Kremastinos DT, Stefanakis GS, Iliodromitis EK, Avrambos GT, Livanis EG, et al: The effectiveness of beta-blockade and its influence on heart rate variability in vasovagal patients. Eur Heart J 1993; 14: 1499-1507

11. Kochiadakis GE, Orfanakis A, Chryssostomakis SI, Manios EG, Kounali DK, Vardas PE: Autonomic nervous system activity during tilt testing in syncopal patients, estimated by power spectral analysis of heart rate variability. Pacing Clin Electrophysiol 1997; 20: 1332-1341

12. Morillo CA, Klein GJ, Jones DL, Yee R: Time and frequency domain analyses of heart rate variability during orthostatic stress in patients with neurally mediated syncope. Am J Cardiol 1994; 74: 1258-1262

13. Vardas P, Kochiadakis G, Orfanakis A, Kalaitzakis M, Manios E: Intraindividudal reproducibility of heart rate variability before and during postural tilt in patients with syncope of unknown origin. Pacing Clin Electrophysiol 1994; 17: 2207-2210

14. Pruvot E, Vesin JM, Schlaepfer J, Fromer M, Kappenberger L: Autonomic imbalance assessed by heart rate variability analysis in vasovagal syncope. Pacing Clin Electrophysiol 1994; 17: 2201-2206

15. Boulos M, Barron S, Nicolski E, Markiewicz W: Power spectral analysis of heart rate variability during upright tilt test: A comparison of patients with syncope and normal subjects. Cardiology 1996; 87: $28-32$

16. Task Force of the European Society of Cardiology and the North American Society of Pacing and Electro physiology: Heart rate variability: Standards of measurement, physiological interpretation, and clinical use. Circulation 1996; 93: 1043-1065

17. Abboud FM: Neurocardiogenic syncope. $N$ Engl J Med 1993; 328: $1117-1120$

18. Sneddon JF, Counihan PJ, Bashir Y, Haywood GA, Ward DE, Camm $\mathrm{AJ}$ : Assessment of autonomic function in patients with neurally mediated syncope: Augmented cardiopulmonary baroreceptor responses to graded orthostatic stress. J Am Coll Cardiol 1993; 21: 1193-1198

19. Sra JS, Murthy V, Natale A, Jazayeri MR, Dhala A, Deshpande S, et al: Circulatory and catecholamine changes during head-up tilt testing in neurocardiogenic (vasovagal) syncope. Am J Cardiol 1994; 73: $33-$ 37

20. Abe H, Kobayashi H, Nakashima Y, Izumi F, Kuroiwa A: Plasma catecholamines and cyclic AMP response during head-up tilt test in patients with neurocardiogenic (vasodepressor) syncope. Pacing Clin Electrophysiol 1995; 18: 1419-1426

21. Wallin BG, Sundlöf G: Sympathetic outflow in muscles during vasovagal syncope. J Auton Nerv Syst 1982; 6: 287-291

22. Klingenheben T, Kalkusche D, Li YG, Schöpperl M, Hohnloser SH: Changes in plasma epinephrine concentration and in heart rate during head-up tilt testing in patients with neurocardiogenic syncope: Correlation with successful therapy with beta-receptor antagonists. $J$ Cardiovasc Electrophysiol 1996; 7: 802-808

23. Pomeranz B, Macaulay RJB, Caudill MA, Kutz I, Adam D, Gordon $\mathrm{D}$, et al: Assessment of autonomic function in humans by heart rate spectral analysis. Am J Physiol 1985; 248: H151-H153

24. Vybiral T, Bryg RJ, Maddens ME, Boden WE: Effect of passive tilt on sympathetic and parasympathetic components of heart rate variability in normal subjects. Am J Cardiol 1989; 63: 1117-1120

25. Kaufman ES, Bosner MS, Bigger JT, Stein PK, Kleiger RE, Rolnitzky LM, et al: Effects of digoxin and enalapril on heart period variability and response to head-up tilt in normal subjects. Am J Cardiol 1993; 72: $95-99$

26. Malliani A, Lombardi F, Pagani M: Power spectrum analysis of heart rate variability: A tool to explore neural regulatory mechanisms. $\mathrm{Br}$ Heart J 1994; 71: 1-2

27. Pagani M, Lombardi F, Guzzetti S, Rimoldi O, Furlan R, Pizzinelli $\mathrm{P}$, et al: Power spectral analysis of heart rate and arterial pressure variabilities as a marker of sympatho-vagal interaction in man and conscious dog. Circ Res 1986; 59: 178-193

28. Bloomfield DM, Bigger JT, Pavri BB, Han J, Fleiss JL, Rolnitzky LM, et al: Vagal modulation of RR intervals during head-up tilt and the infusion of isoproterenol. Am J Cardiol 1995; 75: 1145-1150

29. Malliani A, Pagani M Lombardi Federico, Cerutti S: Cardiovascular neural regulation explored in the frequency domain. Circulation 1991; 84: $482-492$

30. Morillo CA, Eckberg DL, Ellenbogen KA, Beightol LA, Hoag JB, Tahvanainen KUO, et al: Vagal and sympathetic mechanisms in patients with orthostatic vasovagal syncope. Circulation 1997; 96: $2509-2513$ 